Research Article

Open Access

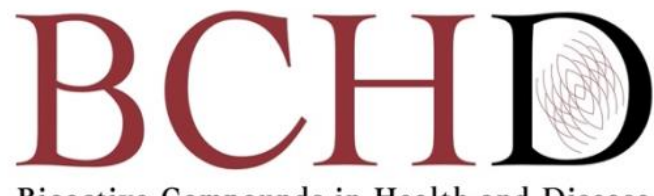

Bioactive Compounds in Health and Disease

\title{
The effect of amaranth oil on autoantibodies in lupus prone mice
}

\section{Danik Martirosyan ${ }^{1,2}$, Jack Hutcheson ${ }^{1}$, Deena Sajitharan ${ }^{1}$, Samantha Williams ${ }^{2}$, Chandra \\ Mohan $^{1}$}

${ }^{1}$ Department of Internal Medicine, The University of Texas Southwestern Medical Center, Dallas, TX, USA; ${ }^{2}$ Functional Food Center/Functional Food Institute, Dallas, TX, USA

*Corresponding Author: Danik Martirosyan, PhD, Functional Food Center/Functional Food Institute, Dallas, TX, USA

Submission Date: September 29 th 2021; Acceptance Date: October 27 ${ }^{\text {th }}, 2021$; Publication Date: October $28^{\text {th }}, 2021$

Please cite this as: Martirosyan D., Hutcheson J., Sajitharan D., Williams S., Mohan C. The effect of amaranth oil on autoantibodies in lupus prone mice. Bioactive Compounds in Health and Disease 2021; 4(10): 226-239. DOI: https://www.doi.org/10.31989/bchd.v4i10.847

\section{ABSTRACT \\ Background: Autoimmune diseases, such as systemic lupus erythematosus, can have severe impacts on quality of life. They are one of the leading causes of death for women in the United States. Distinguished amaranth oil \\ Autoantibody absorbances
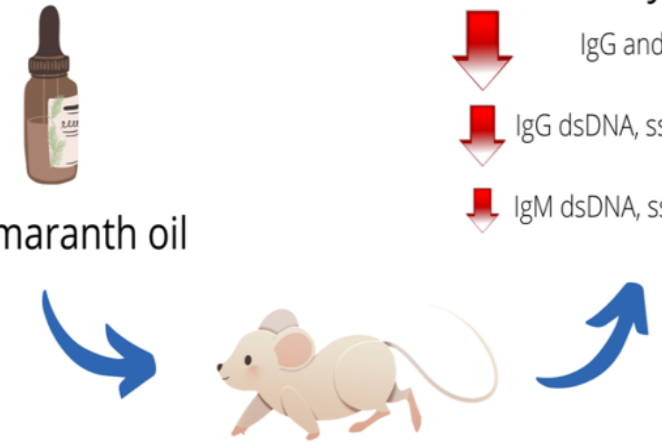 \\ lupus prone mice \\ immunosuppressant drugs, which can have adverse effects. \\ Aim of Study: Amaranth is a good functional food candidate, possessing antioxidants, bioactive compounds, and a variety of health benefits, such as lowering cholesterol, and aiding diabetes and hypertension. Previous studies have largely focused on the grain or seed, but amaranth oil is less explored. This study examines whether orally}


administered amaranth oil had any effects on autoantibodies and splenic immune cell populations in murine subjects.

Methods: Mice in the experimental group $(n=3)$ were given $4 \mu$ of amaranth oil per gram of mouse weight for 5 days a week over 84 days. Control mice $(n=2)$ were sham treated on the same schedule with no oil. To determine autoantibody levels, enzyme-linked immunosorbent assays (ELISAs) were first conducted on wells pre-coated with double stranded DNA, single stranded DNA, histones, or double stranded DNA and then histones (nucleosomes). Autoantibody presence was quantified by measuring absorbance at $405 \mathrm{~nm}$. Splenic cell populations were examined with flow cytometry and compared using a student's t-test.

Results: Compared to the control group, the mice receiving amaranth oil showed decreased IgG and IgM histone autoantibody absorbance levels throughout the whole study. IgG dsDNA, ssDNA, and nucleosome autoantibody absorbances were lower than that of the control group for the first 42 days. IgM dsDNA, ssDNA, and nucleosome autoantibody absorbances were lower only for the first 14 days. There were no significant differences found amongst splenic immune cell populations between the control and experimental groups.

Conclusion: These preliminary data show that amaranth oil may help decrease autoantibody levels in lupus prone murine subjects. However, given the small number of subjects in this study, further research is needed to confirm observed effects and determine the most effective dose and administration schedule.

Keywords: autoantibody, IgG, IgM, histone, dsDNA, ssDNA, nucleosome, amaranth oil, immunoglobulin, lupus

CFFC 2021. This is an Open Access article distributed under the terms of the Creative Commons Attribution 4.0 License (http://creativecommons.org/licenses/by/4.0)

\section{INTRODUCTION}

Autoimmune diseases, such as systemic lupus erythematosus (SLE), can have chronic debilitating effects and thus significant impacts on quality of life. They are one of the leading causes of death for young and middle-aged women in the United States [1-2]. Autoimmune diseases encompass a wide variety of diseases that afflict people from all backgrounds and are estimated to affect $2.5-5 \%$ of the general population [3-6]. Treatments generally include immunosuppressants. Immunosuppressant drugs have a range of side effects; after receiving high doses, side effects can become more severe and treatments can lose their efficacy [7]. Finding functional food natural alternatives with bioactive compounds and potentially less severe side effects would therefore be beneficial.

The adaptive immune system utilizes a group of leukocytes, the lymphocytes. Particularly, T and B lymphocytes (T cells and B cells) recognize antigens; B cells produce immunoglobulins (Ig), or circulating antibodies, while T cells are more involved with 
intracellular pathogens and regulating immune responses [8]. The five isotypes include $\lg G, \lg M, \lg A$, $\lg D$, and $\lg E$. IgM and $\lg G$ in particular are known to fight against infections [9-10]. Autoantibodies are defined as immunoglobulins that attack self-antigens and are a distinguishing factor in autoimmune diseases [9, 11]. While autoantibodies are also observed in healthy individuals, their presence also plays an important role in disease likelihood, diagnosis, prognosis, and even tissue damage $[3,6$, 12]. Diseases such as type 1 diabetes and adrenalitis are identified as autoimmune based on autoantibody levels. Antinuclear antibodies (ANAs) and IgG antibodies to dsDNA are often present in cases of systemic lupus erythematosus (SLE) and rheumatoid arthritis [12]. They have even previously been shown to precede clinical onset of SLE and rheumatic diseases [13]. Because of their high specificity, antibodies against double-stranded (ds) DNA are considered the most characteristic marker for diagnosing SLE [14-17]. However, they are also associated with renal disease, rheumatoid arthritis, HIV, type 1 autoimmune hepatitis, myeloma, parvovirus B19 [15, 18-19]. Similarly, antinucleosome antibodies are associated with SLE, rheumatoid arthritis, Sjögren's syndrome, and systemic sclerosis [15, 17, 20-21]. Anti-histone antibodies have been associated with SLE, rheumatoid arthritis, systemic sclerosis, Alzheimer's disease, dementia, autoimmune hepatitis, druginduced lupus, primary biliary cirrhosis, infection, as well as linear sclerosis severity [15, 17, 22-25]. Anti single-stranded (ss) DNA antibodies are an indicator of flares in SLE, linear sclerosis severity, and have been correlated to preeclampsia and malaria [24, 2628]. Enzyme-linked immunosorbent assay (ELISA) is one of the most common methods used in detecting autoantibodies [29].

Amaranth is an increasingly popular tropical plant dating back to the Aztecs, Inca, and Maya, who consumed it in their daily diet [30-31]. Amaranth has previously been shown to have antioxidants and possess a variety of health benefits, such as lowering cholesterol, and aiding diabetes and hypertension [32-34]. These properties stem from amaranth being rich in monosaturated fatty acids, polyunsaturated fatty acids, squalene, linoleic acids, tocopherols, and essential amino acids [32-33, 35]., Squalene and tocopherol are antioxidative, resulting in high oxidative stability in amaranth oil [35]. Past researchers have shown that amaranth can decrease total cholesterol and low density lipoprotein; the hypocholesterimic effect has been attributed to squalene, fatty acids, proteins, amino acids, as well as a combination of constituents [33]. Amaranth was shown to decrease blood glucose and increase serum insulin in streptozocin-induced rats [33-34]. Notably, conjugated linoleic acid has previously been shown to decrease signs of SLE, including autoantibodies and splenomegaly [36]. Moreover, compared to other cereals, amaranth has a high proportion of lysine and tryptophan, rivaling that of animal sources $[33,35$, 37].

It was also recently found that amaranth proteins contain bioactive peptides, making amaranth a strong functional food candidate [38-39]. 
A few studies examined foods containing amaranth and found that consuming these products still resulted in antihypertensive effects [39-43]. Additionally, amaranth somewhat maintains its favorable composition even after being cooked, raising the possibility that it can be incorporated in functional food products. Puffing or popping Amaranthus cruentus seeds reduced unsaturation levels ( 75.5 to $62.3 \%$ ), and linoleic acid (46.8 to $27 \%$ ), but increased squalene by $15.5 \%$ [44-45]. Popping and cooking decreased lipid contents in A. cruentus seeds by 1.7 and $3.7 \%$, respectively [45-46]. $A$. cruentus flour maintained its unsaturated fatty acid levels at $75.44 \%$, and amaranth oil exhibited oxidation stability better than sunflower oil $[45,47]$. In terms of immune effects, Hibi et al. found that amaranth can inhibit IgE production and therefore possibly allergies [48-49]. This study examines the effect of amaranth oil on autoantibody and splenic cell population levels.

\section{METHODS and MATERIALS}

Mice: B6.Sle1.Sle2.Sle3 mice $(n=5)$ were bred and housed at University of Texas Southwestern Medical Center. Mice were aged to 7-9 months of age prior to the start of the study and all experiments were performed on male mice. All studies were conducted with the prior approval of the University of Texas Southwestern Medical Center Institutional Animal Care and Use Committee.

Amaranth Oil Treatment: Amaranth oil extracted from Amaranthus hybridus L. (Amaranthaceae) was obtained from Russian Oliva. Mice in the experimental group $(n=3)$ received $4 \mu$ l of amaranth oil per gram of mouse weight by oral gavage 5 days per week over the course of 84 days. Control mice ( $n$ $=2$ ) were sham treated on the same schedule with an oral gavage needle containing no oil.

Autoantibody ELISAs: Serum was collected from the mice biweekly and assayed for the presence of nuclear autoantibodies. Briefly, samples were added into 96-well plates pre-coated with double stranded DNA, single stranded DNA, histones, or double stranded DNA and then histones (nucleosomes). An alkaline phosphatase-conjugated anti-IgG or anti-IgM secondary antibody was then added to the plate and autoantibody titers were determined by the absorbance read at $405 \mathrm{~nm}$ on an ELx808 plate reader (BioTek, Winooski, VT) horseradish peroxidaseconjugated rabbit anti-mouse IgG or IgM antibodies were added.

Flow cytometry: At the conclusion of the 84 days of study, spleens were isolated from mice following sacrifice and perfusion. A single cell suspension was obtained by crushing the spleen through a 100micron mesh filter and washing the cells with DMEM. Red blood cells were lysed using PharmLyse (BD Biosciences, San Diego, CA). Cells were stained with antibodies against AA4.1, B220, CD4, CD5, CD8, CD11b, CD11c, CD21/35, CD23, CD45, CD62L, CD69, CD80, CD138, GL-7, Gr-1, I-A/IE (BD Biosciences, San Diego, CA) and F4/80 (Invitrogen, San Diego, CA). All samples were run on an LSRII flow cytometer (BD 
Biosciences, San Diego, CA) in the University of Texas Southwestern Medical Center Flow Cytometry Core.

Statistics: All statistical analyses were done using a two-tailed Student's T-test with Welch's correction.

\section{RESULTS}

Autoantibodies: The group receiving $4 \mu \mathrm{l}$ of amaranth oil for 5 days a week showed decreased absorbances for all autoantibodies studied for the first 14 days. However, only the IgG (Figure 1A, Table 1A) and IgM (Figure 1B, Table 1B) histone autoantibody absorbances were lower throughout the entire 84 days of study. For IgG dsDNA, ssDNA, and nucleosome, absorbances were lower for only the first 42 days. After the 42 nd day, as depicted in Figure 2A and Table 2A, IgG dsDNA autoantibody absorbance increased to higher than that of the control before decreasing after the 70th day; the same was observed for IgG ssDNA (Figure 2B and Table 2B). Illustrated in Figure 2C and Table 2C, IgG nucleosome autoantibody absorbance was lower in the experimental group for the first 56 days before increasing to above that of the control, then decreasing after the 70th day. As shown in Figure 3A and Table 3A, IgM dsDNA absorbance was lower in the experimental group for the first 28 days before increasing to approximately the same or higher than the control. Displayed in Figure 3B and Table 3B, IgM ssDNA absorbances were lower in the experimental group for only the first 14 days; the same was seen with IgM nucleosome (Figure 3C and Table 3C). After the 14th day, these absorbances generally were higher or the same as that of the control group.

Table 1A. Average IgM histone autoantibody absorbance levels for control, experimental group, and their differences over the 84 days of experimentation.

\begin{tabular}{|lllllllll|} 
& D0 & D14 & D28 & D42 & D56 & D70 & D84 \\
\hline $\mathbf{0} \boldsymbol{\mu l} / \mathrm{g}$ & 0.5075 & 0.65 & 0.6925 & 0.4415 & 0.672 & 0.527 & 0.58 \\
\hline $\mathbf{\mu l} / \mathrm{g}$ & 0.3575 & 0.401333 & 0.363 & 0.403 & 0.4615 & 0.3735 & 0.4505 \\
\hline Differences & 0.15 & 0.248667 & 0.3295 & 0.0385 & 0.2105 & 0.1535 & 0.1295 \\
\hline
\end{tabular}

Table 1B. Average IgG histone autoantibody absorbance levels for control, experimental group, and their differences over the 84 days of experimentation.

\begin{tabular}{|lllllllll|} 
& D0 & D14 & D28 & D42 & D56 & D70 & D84 \\
\hline O $\mu \mathrm{l} / \mathrm{g}$ & 0.2035 & 0.353 & 0.324 & 0.249 & 0.3295 & 0.1855 & 0.2885 \\
\hline $\mathbf{4} \mathrm{l} / \mathrm{g}$ & 0.125 & 0.112333 & 0.127 & 0.1875 & 0.1995 & 0.142 & 0.1465 \\
\hline Differences & 0.0785 & 0.240667 & 0.197 & 0.0615 & 0.13 & 0.0435 & 0.142 \\
\hline
\end{tabular}



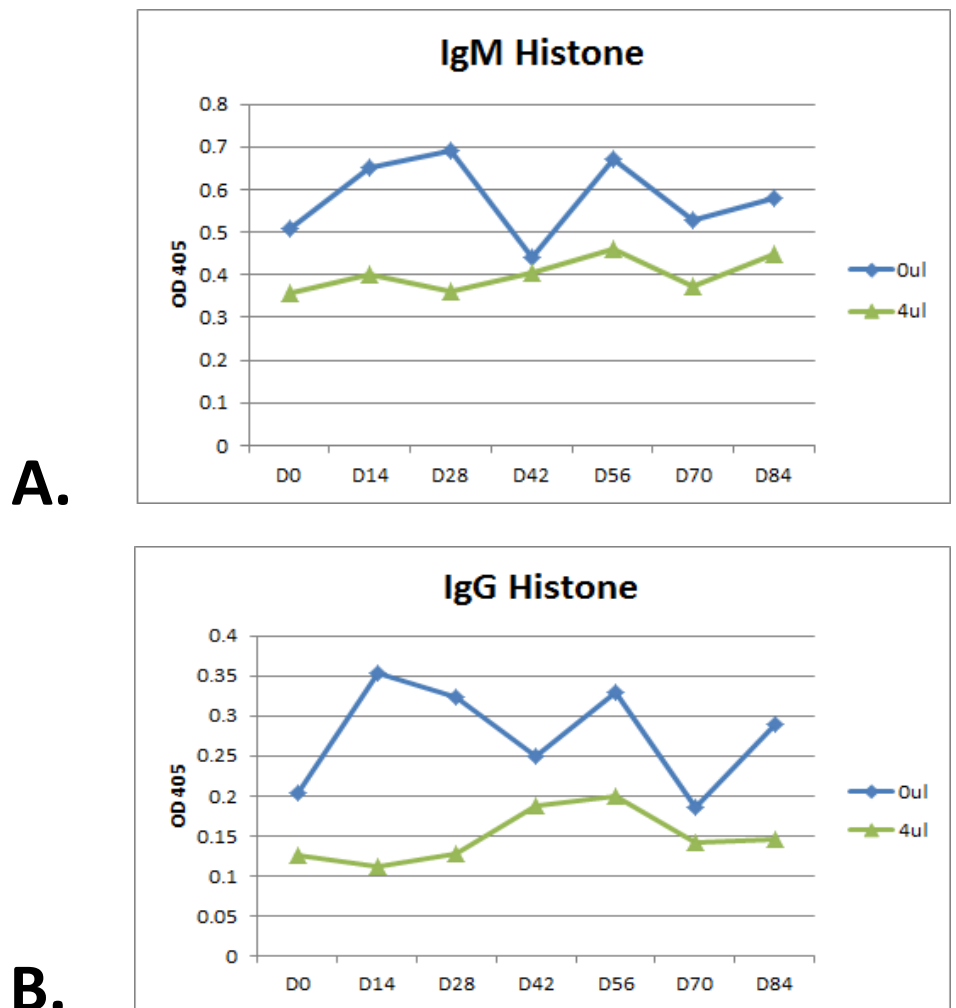

Figure 1A, 1B. Average IgM and IgG histone autoantibody absorbance levels for control and experimental groups over the 84 days of experimentation.

Table 2A. Average IgG dsDNA absorbance levels for control, experimental group, and their differences over the 84 days of experimentation.

\begin{tabular}{|llllllll|} 
& D0 & D14 & D28 & D42 & D56 & D70 & D84 \\
\hline $\mathbf{0} \mu \mathrm{l} / \mathrm{g}$ & 0.708 & 0.69 & 0.612 & 0.622 & 0.6005 & 0.754 & 0.587 \\
\hline $\mathbf{4} \boldsymbol{\mu l} / \mathrm{g}$ & 0.3945 & 0.388667 & 0.436 & 0.5015 & 0.682 & 0.701 & 0.6675 \\
\hline Differences & 0.3135 & 0.301333333 & 0.176 & 0.1205 & -0.0815 & 0.053 & -0.0805 \\
\hline
\end{tabular}

Table 2B. Average IgG ssDNA absorbance levels for control, experimental group, and their differences over the 84 days of experimentation.

\begin{tabular}{|llllllll|} 
& D0 & D14 & D28 & D42 & D56 & D70 & D84 \\
\hline O $\mu \mathrm{l} / \mathrm{g}$ & 0.8985 & 0.925 & 0.8525 & 0.8485 & 0.8255 & 0.877 & 0.823 \\
\hline $\mathbf{4} \boldsymbol{\mu l} / \mathrm{g}$ & 0.614 & 0.612 & 0.725667 & 0.7255 & 0.8525 & 0.9495 & 0.793 \\
\hline Differences & 0.2845 & 0.313 & 0.126833 & 0.123 & -0.027 & -0.0725 & 0.03 \\
\hline
\end{tabular}

Table 2C. Average IgG nucleosome absorbance levels for control, experimental group, and their differences over the 84 days of experimentation.

\begin{tabular}{|c|c|c|c|c|c|c|c|}
\hline & DO & D14 & D28 & D42 & D56 & D70 & D84 \\
\hline $0 \mu \mathrm{l} / \mathrm{g}$ & 0.753 & 0.752 & 0.645 & 0.712 & 0.574 & 0.6125 & 0.6665 \\
\hline $4 \mu \mathrm{l} / \mathrm{g}$ & 0.5235 & 0.471333 & 0.483 & 0.535 & 0.52 & 0.6645 & 0.671 \\
\hline Differences & 0.2295 & 0.280667 & 0.162 & 0.177 & 0.054 & -0.052 & -0.0045 \\
\hline
\end{tabular}




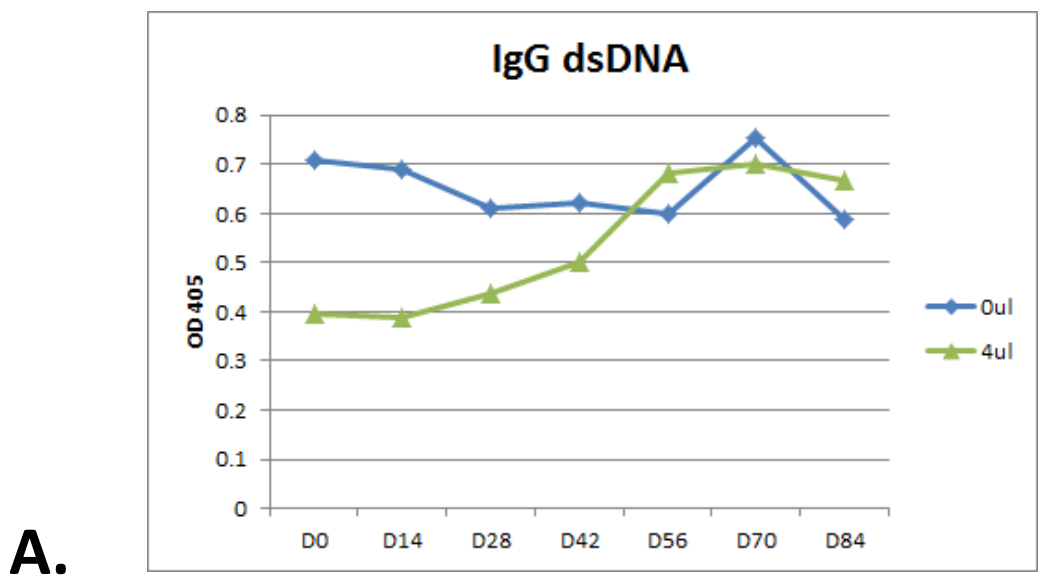

B.

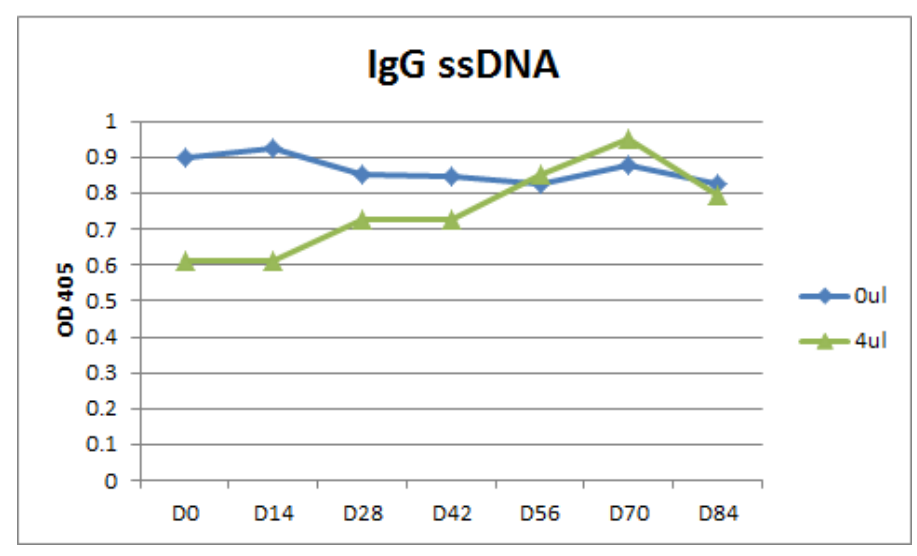

C.

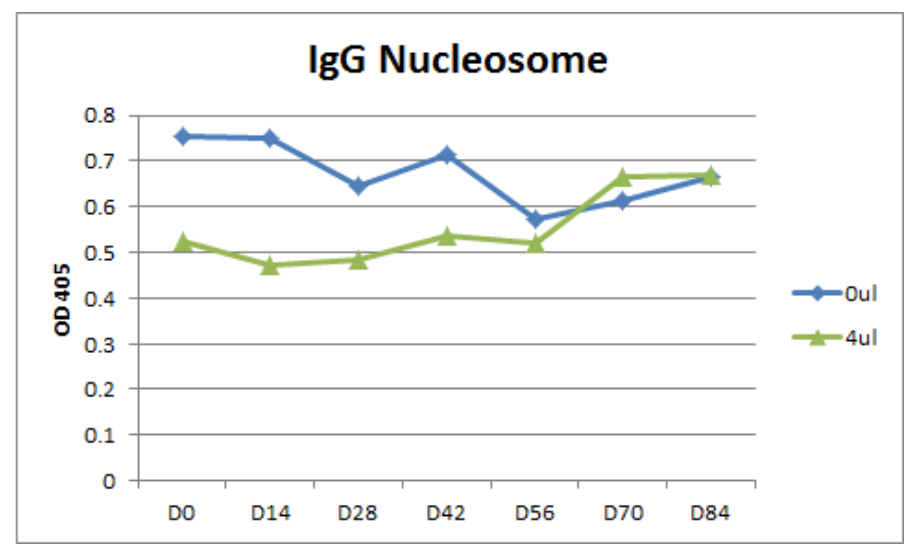

Figure 2A, 2B, 2C. Average IgG dsDNA, ssDNA, and nucleosome absorbance levels for control and experimental groups over the 84 days of experimentation.

Table 3A. Average IgM dsDNA absorbance levels for control, experimental group, and their differences over the 84 days of experimentation.

\begin{tabular}{|lllllllll} 
& D0 & D14 & D28 & D42 & D56 & D70 & D84 \\
\hline $\mathbf{0} \mu \mathrm{l} / \mathrm{g}$ & 0.4315 & 0.6035 & 0.448 & 0.4265 & 0.4015 & 0.374 & 0.238 \\
\hline $\mathbf{4} \mathrm{l} / \mathrm{g}$ & 0.348 & 0.504667 & 0.424 & 0.4495 & 0.4165 & 0.516 & 0.516 \\
\hline Differences & 0.0835 & 0.098833 & 0.024 & -0.023 & -0.015 & -0.142 & -0.278 \\
\hline
\end{tabular}


Table 3B. Average IgM ssDNA absorbance levels for control, experimental group, and their differences over the 84 days of experimentation.

\begin{tabular}{|c|c|c|c|c|c|c|c|}
\hline & Do & D14 & D28 & D42 & D56 & D70 & D84 \\
\hline $0 \mu l / g$ & 0.5345 & 0.7625 & 0.5065 & 0.6325 & 0.5095 & 0.4285 & 0.6635 \\
\hline $4 \mu \mathrm{l} / \mathrm{g}$ & 0.3335 & 0.563 & 0.542333 & 0.5905 & 0.527 & 0.6525 & 0.789 \\
\hline Differences & 0.201 & 0.1995 & -0.03583 & 0.042 & -0.0175 & -0.224 & -0.1255 \\
\hline
\end{tabular}

Table 3C. Average IgM histone absorbance levels for control, experimental group, and their differences over the 84 days of experimentation.

\begin{tabular}{|llllllll|} 
& D0 & D14 & D28 & D42 & D56 & D70 & D84 \\
\hline $\mathbf{0} \mu \mathrm{l} / \mathrm{g}$ & 0.488 & 0.578 & 0.405 & 0.47 & 0.3875 & 0.4145 & 0.452 \\
\hline $\mathbf{4} \boldsymbol{\mu l} / \mathrm{g}$ & 0.405 & 0.501 & 0.465 & 0.5085 & 0.3685 & 0.5355 & 0.455 \\
\hline Differences & 0.083 & 0.077 & -0.06 & -0.0385 & 0.019 & -0.121 & -0.003 \\
\hline
\end{tabular}

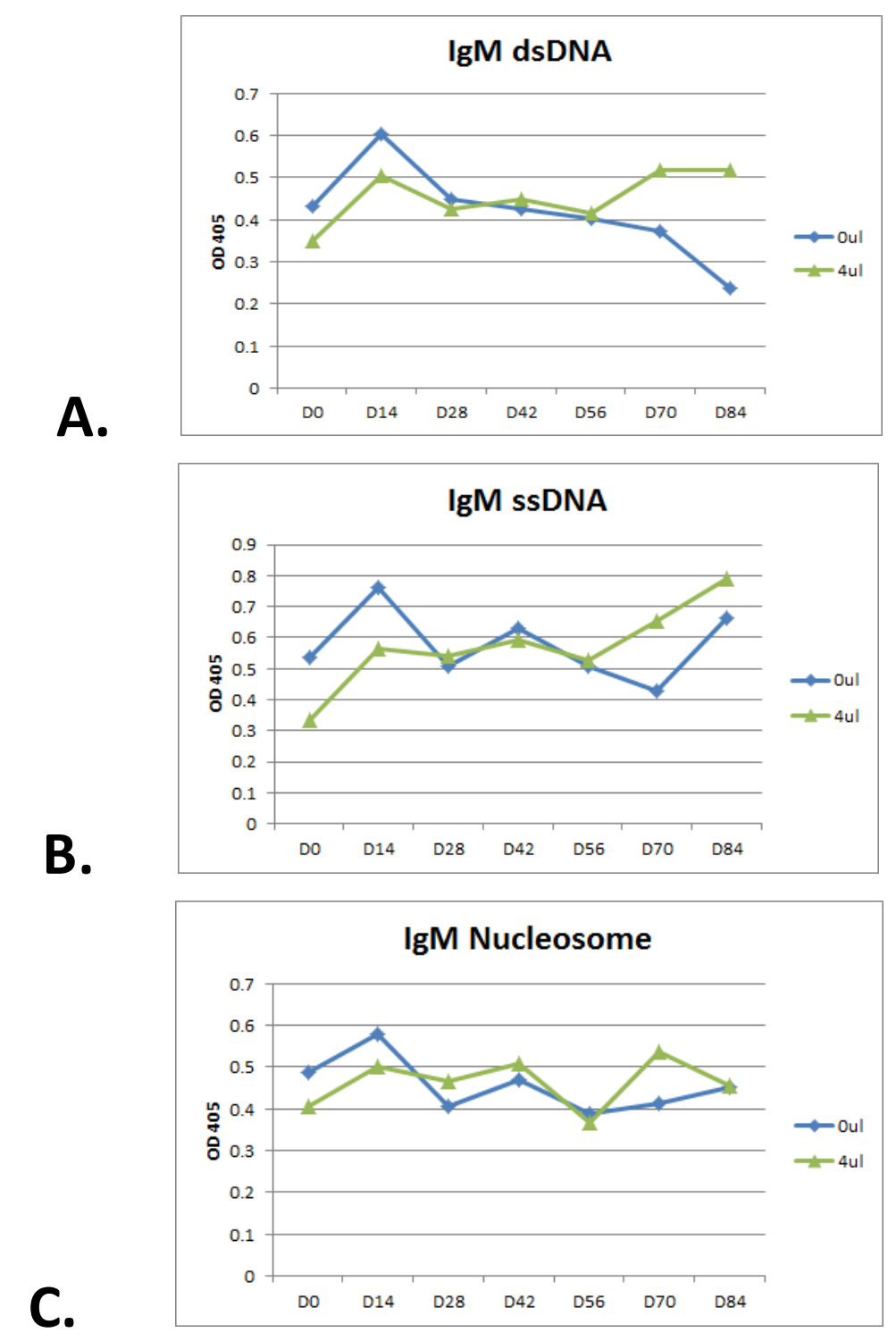

Figure 3A, 3B, 3C. IgM dsDNA, ssDNA, and nucleosome absorbance levels for control and experimental groups over the 84 days of experimentation. 
Flow Cytometry: There were no significant differences found amongst the splenic immune cell populations tested between the control and experimental groups.

\section{DISCUSSION}

Since the sample sizes were so small, the data is preliminary and only limited conclusions can be drawn. The study began with two dosage groups, $4 \mu \mathrm{l}$ and $1 \mu \mathrm{l}$, with three mice each, as well as a control group consisting of two mice. Two mice in the $1 \mu \mathrm{l}$ group passed away, leaving $n=1$ for that group; the data for that one mouse are not reported, but are in line with the presented data. The presented data thus includes $n=3$ for the $4 \mu$ l experimental group and $n=$ 2 for the control group. This study also utilized lupus prone mice, so it is possible that results may differ in non-lupus prone subjects. That being said, the results are intriguing: decreased absorbances for all autoantibodies were observed for the first 14 days in the group receiving $4 \mu \mathrm{l}$ amaranth oil per gram of mouse weight. It has been shown that curcumin can decrease anti-dsDNA levels [50], but similar results with amaranth oil possibly decreasing histone, nucleosome, ssDNA, and dsDNA autoantibodies have not previously been presented. Moreover, fish oil can help lipid metabolism in SLE, in turn aiding immune, atherosclerotic, and inflammatory events, due to its omega-3 polyunsaturated fatty acids [51-53].

Lupus is associated with changes in lipid metabolism, especially increased oxidative stress. Lipid alteration and oxidative stress in turn play a role in $\mathrm{T}$ lymphocyte dysfunctions and systemic inflammation, suggesting lipids are involved in their regulation [51]. Since amaranth oil has previously been shown to reduce oxidative stress and is rich in squalene and polyunsaturated fatty acids [32, 48, 54], the decreased autoantibody levels make sense. n-3 polyunsaturated fatty acids are known to suppress antigen presentation, as well as $\mathrm{T}$ cell activation and proliferation [55-58]. Including polyunsaturated fatty acids in the diet also has immunosuppressive effects [56-58].

Absorbances for IgG nucleosome, ssDNA, and dsDNA autoantibodies were lower than the control for the first 42 days. As previously mentioned, antinucleosome, anti-ssDNA, and anti-dsDNA autoantibodies are associated with various diseases or disease severity. Anti-dsDNA, in particular, strongly correlates to disease activity for all isotypes [59]. Normal subjects generally have IgM ssDNA antibodies, but IgG antibodies to dsDNA are less frequent [60]. IgG anti-dsDNA antibodies are a distinguishing factor in SLE and are generally believed to play a role in the pathogenesis of SLE. They also have a relationship with nephritis disease activity [61]. Though anti-dsDNA autoantibodies are specific for SLE diagnosis, anti-nucleosome autoantibodies actually have a better correlation with SLE disease activity and lupus nephritis [25]. In most studies, the sensitivity for anti-nucleosome antibodies was higher than that of anti-dsDNA. As such, it is interesting that all three autoantibodies showed a somewhat similar effect in response to the regular doses of amaranth oil.

One of the most consistent and pronounced effects were observed with IgM and IgG histone autoantibodies; lower absorbances were observed for the entire 84 days of study. This is curious but encouraging since the other autoantibodies measured eventually showed an increase in absorbance. While anti-histone autoantibodies are generally not very pathogenic or useful in disease monitoring/diagnosis, they are often present in 
patients with many autoimmune diseases, particularly SLE, drug-induced lupus, and primary biliary cirrhosis [25, 62-63].

Absorbances for IgM nucleosome, ssDNA, and dsDNA were a little more erratic, but nonetheless were lower for the first 14 days. The inconsistency may be due to IgM's potential protective effects. IgM anti-dsDNA antibodies are present in SLE, rheumatoid arthritis, autoimmune liver disease, and Sjögren's syndrome [61]. While autoantibodies are a hallmark for autoimmune diseases, natural autoantibodies, mostly IgM, are found in healthy individuals [64]. It has even been suggested that mice lacking IgM antibodies could accelerate SLE [64]. IgM antibodies against dsDNA were previously shown to delay proteinuria, reduce renal pathological severity and increase lifespans of lupus prone murine subjects [61]. They also had a very strong negative correlation with glomerulonephritis, and appear to possess a protective effect for nephropathy $[15,61,64]$. Similarly, anti-ssDNA antibody may be related to the severity of hypertension and proteinuria [27].

Previous researchers thought IgM anti-dsDNA antibodies might hinder IgG anti-dsDNA antibody production, leading to milder disease activity and some protection from lupus nephritis $[59,64]$. As such, while amaranth oil may not provide an immunosuppressive effect for $\operatorname{lgM}$ as strong as it seems to for IgG, it is not necessarily a downfall. It may end up being more optimal for prospective treatments.

Though autoantibodies exist in healthy subjects, they are the distinguishing characteristic of autoimmune diseases. Since no cure exists for these diseases, treatment involves immunosuppressants, which can have adverse effects on the patient; so perhaps incorporating amaranth oil into the treatment regimen may be beneficial. Previous researchers have largely focused on the grain or seed, but this study shows amaranth oil may also be valuable.

Amaranth oil is a promising functional food candidate. As noted earlier, it provides several health benefits, exhibits antioxidant protective effects and possesses bioactive compounds, such as squalene. Past researchers demonstrated that it can significantly decrease total cholesterol, low density cholesterol, and triglycerides [32]. It has also been shown to have hepatoprotective effects [65]. The Functional Food Center states a functional food should contain defined bioactive compounds and non-toxic dosages that provide a clinically proven and documented health benefit, utilizing specific biomarkers [66-69]. Resultantly, since our data are preliminary and based on a small sample size, we cannot definitively say whether amaranth or amaranth oil is a functional food in terms of lupus. Future studies should determine if the possible autoantibody lowering effects of amaranth oil are replicable in a larger sample size of lupus prone murine subjects. If confirmed, then clinical studies would be needed to verify amaranth oil effectiveness in decreasing autoantibodies. The most effective dosage and administration schedule should also be determined.

\section{CONCLUSION}

This study demonstrated the potential autoantibody lowering effects of amaranth oil in murine subjects. Given the small sample size, the data are preliminary and future studies are needed to confirm the observed effects. Considering the results and amaranth oil's health properties and bioactive compounds, it is a good functional food candidate. 
Abbreviations: Ig: immunoglobulin, ANA: antinuclear antibody, SLE: systemic lupus erythematosus, dsDNA: double-stranded deoxyribonucleic acid, ssDNA: single-stranded deoxyribonucleic acid

Conflicts of Interest: There are no conflicts of interest associated with this study.

Authors' contribution: The original idea was conceived by DM and was discussed with CM. The main focus and ideas of the experiments finally agreed with $\mathrm{JH}$ and DS. The experiments were conducted and analyzed by DS, JH and DM.

\section{REFERENCES}

1. Cooper GS, Stroehla BC. The epidemiology of autoimmune diseases. Autoimmun Rev 2003, 2(3):119-125. https://www.doi.org/10.1016/S1568-9972(03)00006-5

2. Walsh SJ, Rau LM. Autoimmune diseases: a leading cause of death among young and middle-aged women in the United States. Am J Public Health 2000, 90(9):1463-1466. https://www.doi.org/10.2105/AJPH.90.9.1463

3. Wang L, Wang F-S, Gershwin ME. Human autoimmune diseases: a comprehensive update. J Intern Med 2015, 278(4):369-395. https://www.doi.org/10.1111/joim.12395

4. Jacobson DL, Gange SJ, Rose NR, Graham NMH. Epidemiology and Estimated Population Burden of Selected Autoimmune Diseases in the United States. Clin Immunol Immunopathol. 1997, 84(3):223-243.

https://www.doi.org/10.1006/clin.1997.4412

5. Eaton WW, Rose NR, Kalaydjian A, Pedersen MG, Mortensen PB. Epidemiology of autoimmune diseases in Denmark. J Autoimmun. 2007, 29(1):1-9. https://www.doi.org/10.1016/j.jaut.2007.05.002

6. Ludwig RJ, Vanhoorelbeke K, Leypoldt F, et al. Mechanisms of Autoantibody-Induced Pathology. Front Immunol 2017, 8:603. https://www.doi.org/10.3389/fimmu.2017.00603

7. Lallana EC, Fadul CE. Toxicities of immunosuppressive treatment of autoimmune neurologic diseases. Curr Neuropharmacol 2011, 9(3):468-477.
Experimental data was analyzed by $\mathrm{DS}$ and $\mathrm{JH}$, and discussed with $\mathrm{DM}$ and $\mathrm{CM}$. The main text of the paper including methods were written by $\mathrm{SW}, \mathrm{JH}$, and DM. The manuscript was revised, edited, and formatted by DM and SW.

Acknowledgement: We would like to thank the Department of Internal Medicine at The University of Texas Southwestern Medical Center for their support, making this scientific investigation related to the effect of amaranth oil on proteinuria in lupus prone mice possible.

https://www.doi.org/10.2174/157015911796557939

8. Male DK, Brostoff J, Roth DB, Roitt I. Immunology. 8. ed. Elsevier Saunders, 2013.

9. Fereidan-Esfahani $M$, Nayfeh $T$, Warrington $A$, Howe $C L$, Rodriguez M. IgM Natural Autoantibodies in Physiology and the Treatment of Disease. In: Steinitz $M$, ed. Human Monoclonal Antibodies. Vol 1904. Methods in Molecular Biology. Springer New York; 2019:53-81. https://www.doi.org/10.1007/978-1-4939-8958-4_3

10. Mosby, Inc, ed. Mosby's Dictionary of Medicine, Nursing \& Health Professions. Tenth edition. Elsevier; 2017.

11. Aggarwal A. Role of autoantibody testing. Best Pract Res Clin Rheumatol 2014, 28(6):907-920. https://www.doi.org/10.1016/j.berh.2015.04.010

12. Leslie D, Lipsky P, Notkins AL. Autoantibodies as predictors of disease. J Clin Invest 2001, 108(10):1417-1422. https://www.doi.org/10.1172/JCl14452

13. Damoiseaux J, Andrade LE, Fritzler MJ, Shoenfeld Y. Autoantibodies 2015: From diagnostic biomarkers toward prediction, prognosis and prevention. Autoimmun Rev 2015, 14(6):555-563. https://www.doi.org/10.1016/j.autrev.2015.01.017

14. Keyhani J, Keyhani E. Detection of DNA Autoantibodies by Electrophoretic Mobility Shift Assay. In: Houen G, ed. 
Autoantibodies Vol 1901. Methods in Molecular Biology. Springer New York; 2019:133-152.

https://www.doi.org/10.1007/978-1-4939-8949-2 11

15. Cozzani E, Drosera M, Gasparini G, Parodi A. Serology of Lupus Erythematosus: Correlation between Immunopathological Features and Clinical Aspects. Autoimmune Dis 2014, 2014:1-13. https://www.doi.org/10.1155/2014/321359

16. Wang X, Xia Y. Anti-double Stranded DNA Antibodies: Origin, Pathogenicity, and Targeted Therapies. Front Immunol 2019, 10:1667.

https://www.doi.org/10.3389/fimmu.2019.01667

17. Didier K, Bolko L, Giusti D, et al. Autoantibodies Associated With Connective Tissue Diseases: What Meaning for Clinicians? Front Immunol 2018, 9:541. https://www.doi.org/10.3389/fimmu.2018.00541

18. Hansen KE, Arnason J, Bridges AJ. Autoantibodies and common viral illnesses. Semin Arthritis Rheum 1998, 27(5):263-271.https://www.doi.org/10.1016/S0049$\underline{0172(98) 80047-4}$

19. Isenberg DA, Manson JJ, Ehrenstein MR, Rahman A. Fifty years of anti-ds DNA antibodies: are we approaching journey's end? Rheumatology. 2007, 46(7):1052-1056. https://www.doi.org/10.1093/rheumatology/kem112

20. Quattrocchi $P$, Barrile $A$, Bonanno $D$, et al. The role of antinucleosome antibodies in systemic lupus erythematosus. Results of a study of patients with systemic lupus erythematosus and other connective tissue diseases. Reumatismo 2011, 57(2):109-113.

https://www.doi.org/10.4081/reumatismo.2005.109

21. Bruns A, Bläss S, Hausdorf G, Burmester GR, Hiepe F. Nucleosomes are major $\mathrm{T}$ and $\mathrm{B}$ cell autoantigens in systemic lupus erythematosus. Arthritis Rheum 2000, 43(10):2307-2315. https://www.doi.org/10.1002/15290131(200010)43:10<2307::AID-ANR19>3.0.CO;2-J

22. Marks SD, Tullus K. Autoantibodies in systemic lupus erythematosus. Pediatr Nephrol 2012, 27(10):1855-1868. https://www.doi.org/10.1007/s00467-011-2078-4

23. Boveda-Ruiz D, Vilas-Pio B, Freire-Dapena M, et al. AB1012 Clinical utility of antihistone antibodies: a descriptive study. Ann Rheum Dis 2017, 76(Suppl 2):1409. https://www.doi.org/10.1136/annrheumdis-2017eular.3005

24. Arkachaisri T, Fertig N, Pino S, Medsger TA. Serum Autoantibodies and Their Clinical Associations in Patients with Childhood- and Adult-Onset Linear Scleroderma. A Single-Center Study. J Rheumatol 2008, 35(12):2439-2444. https://www.doi.org/10.3899/jrheum.080098

25. Shoenfeld Y, Meroni PL, Gershwin ME. Autoantibodies. 3rd ed. $\quad$ Elsevier; 2014. https://ebookcentral.proquest.com/lib/ufl/detail.action?d ocID=1574447

26. Reveille JD. Predictive value of autoantibodies for activity of systemic lupus erythematosus. Lupus 2004, 13(5):290-297. https://www.doi.org/10.1191/0961203303lu1015oa

27. Yamamoto T, Yoshimura S, Geshi Y, Sasamori Y, Mori H, Kobayashi T. Anti-ssDNA and dsDNA Antibodies in Preeclampsia. Asia Oceania J Obstet Gynaecol 2010, 20(1):93-99.https://www.doi.org/10.1111/j.14470756.1994.tb00427.x

28. Adu D, Williams DG, Quakyi IA, et al. Anti-ssDNA and antinuclear antibodies in human malaria. Clin Exp Immunol 1982, 49(2):310-316.

29. Cressey R, Pimpa S, Chewaskulyong B, et al. Simplified approaches for the development of an ELISA to detect circulating autoantibodies to p53 in cancer patients. BMC Biotechnol 2008, 8(1):16. https://www.doi.org/10.1186/1472-6750-8-16

30. Coelho LM, Silva PM, Martins JT, Pinheiro AC, Vicente AA. Emerging opportunities in exploring the nutritional/functional value of amaranth. Food Funct 2018, 9(11):5499-5512. https://www.doi.org/10.1039/C8FO01422A

31. Tucker JB. Amaranth: The Once and Future Crop. BioScience 1986, 36(1):9-13. https://www.doi.org/10.2307/1309789

32. Martirosyan DM, Miroshnichenko LA, Kulakova SN, Pogojeva AV, Zoloedov VI. Amaranth oil application for coronary heart disease and hypertension. Lipids Health Dis 2007, 6(1):1. https://www.doi.org/10.1186/1476-511X-6-1

33. Chmelík Z, Šnejdrlová M, Vrablík M. Amaranth as a potential dietary adjunct of lifestyle modification to improve cardiovascular risk profile. Nutr Res 2019, 72:36-45. https://www.doi.org/10.1016/j.nutres.2019.09.006

34. Kim HK, Kim MJ, Cho HY, Kim E-K, Shin DH. Antioxidative and anti-diabetic effects of amaranth (Amaranthus esculantus) in streptozotocin-induced diabetic rats. Cell Biochem Funct 2006, 24(3):195-199. https://www.doi.org/10.1002/cbf.1210

35. Nasirpour-Tabrizi P, Azadmard-Damirchi S, Hesari J, PiraviVanak Z. Amaranth Seed Oil Composition. In: Y. Waisundara 
V, ed. Nutritional Value of Amaranth. IntechOpen; 2020. https://www.doi.org/10.5772/intechopen.91381

36. Bergamo P, Luongo D, Maurano F, Mazzarella G, Stefanile R, Rossi M. Conjugated linoleic acid enhances glutathione synthesis and attenuates pathological signs in MRL/MpJFas(lpr) mice. J Lipid Res 2006, 47(11):2382-2391. https://www.doi.org/10.1194/jlr.M600187-JLR200

37. Pond WG, Lehmann JW, Elmore R, et al. Feeding value of raw or heated grain amaranth germplasm. Anim Feed Sci Technol 1991, 33(3-4):221-236. https://www.doi.org/10.1016/0377-8401(91)90062-W

38. Valenzuela Zamudio F, Segura Campos MR. Amaranth, quinoa and chia bioactive peptides: a comprehensive review on three ancient grains and their potential role in management and prevention of Type 2 diabetes. Crit Rev Food Sci Nutr Published online December 11, 2020:1-15. https://www.doi.org/10.1080/10408398.2020.1857683

39. Nardo $A E$, Suárez $S$, Quiroga $A V$, Añón $M C$. Amaranth as a Source of Antihypertensive Peptides. Front Plant Sci 2020, 11:578631.

https://www.doi.org/10.3389/fpls.2020.578631

40. Ontiveros N, López-Teros V, Vergara-Jiménez M de J, et al. Amaranth-hydrolyzate enriched cookies reduce the systolic blood pressure in spontaneously hypertensive rats. J Funct Foods 2020, 64:103613.

https://www.doi.org/10.1016/j.jff.2019.103613

41. Sabbione AC, Suárez S, Añón MC, Scilingo A. Amaranth functional cookies exert potential antithrombotic and antihypertensive activities. Int J Food Sci Technol 2019, 54(5):1506-1513. https://www.doi.org/10.1111/ijfs.13930

42. Valdez-Meza, Raymundo, Figueroa-Salcido, et al. Pasta Enrichment with an Amaranth Hydrolysate Affects the Overall Acceptability while Maintaining Antihypertensive $\begin{array}{llll}\text { Properties. } & \text { 8oods 2019, } 282 .\end{array}$ https://www.doi.org/10.3390/foods8080282

43. Suárez S, Añón MC. Amaranth proteins emulsions as delivery system of Angiotensin-I converting enzyme inhibitory peptides. Food Hydrocoll 2019, 90:154-161. https://www.doi.org/10.1016/i.foodhyd.2018.11.046

44. Singhal RS, Kulkarni PR. Effect of puffing on oil characteristics of Amaranth (Rajgeera) seeds. J Am Oil Chem Soc 1990, 67(12):952-954.

https://www.doi.org/10.1007/BF02541855

45. Venskutonis PR, Kraujalis P. Nutritional Components of Amaranth Seeds and Vegetables: A Review on Composition,
Properties, and Uses: Nutritional components of amaranth seeds and vegetables.... Compr Rev Food Sci Food Saf 2013, 12(4):381-412.https://www.doi.org/10.1111/1541$\underline{4337.12021}$

46. Gamel TH, Mesallam AS, Damir AA, Shekib LA, Linssen JP. CHARACTERIZATION OF AMARANTH SEED OILS. J Food Lipids 2007, 14(3):323-334. https://www.doi.org/10.1111/j.17454522.2007.00089.x

47. Escudero NL, de ARELLANO ML, Luco JM, Giménez MS, Mucciarelli SI. Comparison of the Chemical Composition and Nutritional Value of Amaranthus cruentus Flour and Its Protein Concentrate. Plant Foods Hum Nutr 2004, 59(1):1521. https://www.doi.org/10.1007/s11130-004-0033-3

48. Caselato-Sousa VM, Amaya-Farfán J. State of Knowledge on Amaranth Grain: A Comprehensive Review. J Food Sci. 2012, 77(4):R93-R104. https://www.doi.org/10.1111/j.17503841.2012.02645.x

49. Hibi M, Hachimura $S$, Hashizume $S$, Obata $T$, Kaminogawa $S$. Amaranth Grain Inhibits Antigen-Specific IgE Production Through Augmentation of the IFN- Response in vivo and in vitro. Cytotechnology 2003, 43(1-3):33-40. https://www.doi.org/10.1023/B:CYTO.0000039908.34387. $\underline{\mathrm{d} 3}$

50. Wahono C, Susianti H, Wahyuni Z, et al. The effect of adding curcumin on vitamin $\mathrm{d} 3$ supplementation on anti-dsdna levels and proteinuria, in sle patients with hypovitamin $\mathrm{d}$. In: Poster Session. Lupus Foundation of America; 2017:A119.2A120.https://www.doi.org/10.1136/lupus-2017$\underline{000215.257}$

51. Ferreira HB, Pereira AM, Melo T, Paiva A, Domingues MR. Lipidomics in autoimmune diseases with main focus on systemic lupus erythematosus. J Pharm Biomed Anal 2019, 174:386-395. https://www.doi.org/10.1016/j.jpba.2019.06.005

52. Phillipson BE, Rothrock DW, Connor WE, Harris WS, Illingworth DR. Reduction of Plasma Lipids, Lipoproteins, and Apoproteins by Dietary Fish Oils in Patients with Hypertriglyceridemia. N Engl J Med 1985, 312(19):12101216.

https://www.doi.org/10.1056/NEJM198505093121902

53. Stork JE, Rahman MA, Dunn MJ. Eicosanoids in experimental and human renal disease. Am J Med 1986, 80(1):34-45. https://www.doi.org/10.1016/0002-9343(86)90930-7

54. Paśko $P$, Bartoń $H$, Zagrodzki $P$, et al. Effect of amaranth seeds in diet on oxidative status in plasma and selected 
tissues of high fructose-fed rats. Food Chem 2011, 126(1):85-90.

https://www.doi.org/10.1016/j.foodchem.2010.10.081

55. Nicolaou A, Mauro C, Urquhart P, Marelli-Berg F. Polyunsaturated Fatty Acid-derived lipid mediators and T cell function. Front Immunol 2014, 5:75. https://www.doi.org/10.3389/fimmu.2014.00075

56. Kew S, Mesa MD, Tricon S, Buckley R, Minihane AM, Yaqoob P. Effects of oils rich in eicosapentaenoic and docosahexaenoic acids on immune cell composition and function in healthy humans. Am J Clin Nutr 2004, 79(4):674681. https://www.doi.org/10.1093/ajcn/79.4.674

57. Thies F, Nebe-von-Caron G, Powell JR, Yaqoob P, Newsholme EA, Calder PC. Dietary Supplementation with $\gamma^{-}$ Linolenic Acid or Fish Oil Decreases T Lymphocyte Proliferation in Healthy Older Humans. J Nutr 2001, 131(7):1918-1927. https://www.doi.org/10.1093/jn/131.7.1918

58. Shaikh SR, Edidin M. Immunosuppressive effects of polyunsaturated fatty acids on antigen presentation by human leukocyte antigen class I molecules. J Lipid Res 2007, 48(1):127-138. https://www.doi.org/10.1194/jlr.M600365JLR200

59. Förger F, Matthias T, Oppermann M, Becker H, Helmke K. Clinical significance of anti-dsDNA antibody isotypes: IgG/IgM ratio of anti-dsDNA antibodies as a prognostic marker for lupus nephritis. Lupus 2004, 13(1):36-44. https://www.doi.org/10.1191/0961203304lu485oa

60. Hahn BH. Antibodies to DNA. Epstein FH, ed. N Engl J Med 1998, 338(19):1359-1368.

https://www.doi.org/10.1056/NEJM199805073381906

61. Witte T. IgM Antibodies Against dsDNA in SLE. Clin Rev Allergy Immunol 2008, 34(3):345-347. https://www.doi.org/10.1007/s12016-007-8046-x

62. Shabana AA, El-Ghawet AE, Machaly SA, Abu Hashim EM, ElKady BA, Shaat R. Anti-chromatin and anti-histone antibodies in Egyptian patients with systemic lupus erythematosus. Clin Rheumatol 2009, 28(6):673-678. https://www.doi.org/10.1007/s10067-009-1130-2

63. Schett G, Smole J, Zimmermann C, et al. The autoimmune response to chromatin antigens in systemic lupus erythematosus: autoantibodies against histone $\mathrm{H} 1$ are a highly specific marker for SLE associated with increased disease activity. Lupus 2002, 11(11):704-715. https://www.doi.org/10.1191/0961203302lu247oa

64. Shoenfeld Y, Toubi E. Protective autoantibodies: Role in homeostasis, clinical importance, and therapeutic potential. Arthritis Rheum 2005, 52(9):2599-2606. https://www.doi.org/10.1002/art.21252

65. Nikolaevsky VA, Martirosyan DM, Muzalevskaya EN, Miroshnichenko LA, Zoloedov VI. Hepatotropic, antioxidant and antitoxic action of amaranth oil. Funct Foods Health Dis 2014, 4(5):159. https://www.doi.org/10.31989/ffhd.v4i5.18

66. Martirosyan D, Kanya H, Nadalet C. Can functional foods reduce the risk of disease? Advancement of functional food definition and steps to create functional food products. Funct Foods Health Dis 2021, 11(5):213. https://www.doi.org/10.31989/ffhd.v11i5.788

67. Sadohara R, Martirosyan D. Functional Food Center's vision on functional food definition and science in comparison to FDA's health claim authorization and Japan's Foods for Specified Health Uses. Funct Foods Health Dis 2020, 10(11):465. https://www.doi.org/10.31989/ffhd.v10i11.753

68. Martirosyan D, Liufu J. FFC's Advancement of the Establishment of Functional Food Science. Funct Foods Health Dis 2020, 10(8). https://www.doi.org/10.31989/ffhd.v10i8.729

69. Martirosyan D, Hutcheson J, Sajitharan D, Williams S, Mohan C. The effect of amaranth oil on proteinuria in lupus prone mice. Funct Food Sci 2021, 1(10):39. https://www.doi.org/10.31989/ffs.v1i10.848 